\title{
Type 2 diabetes as a major risk factor for COVID-19 severity: a meta-analysis
}

Lana C. Pinto ${ }^{1,2}$

https://orcid. org/0000-0003-0954-8622

Marcello C. Bertoluci²

https://orcid.org/0000-0002-8307-3162

\section{DEAR EDITOR,}

Coronavirus disease 2019 (COVID-19) has recently emerged as a rapidly

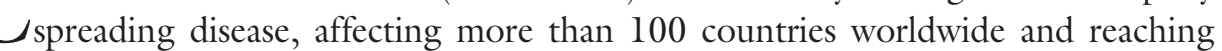
pandemic proportions. The severity of COVID-19 ranges from a mild, self-limiting flu-like illness to a devastating pneumonia culminating in respiratory failure and death. Individuals with diabetes are particularly vulnerable to some respiratory viral infections, such as influenza A $(\mathrm{HlNl})$ infection (1), the severe acute respiratory syndrome (SARS) (2), and the Middle East respiratory syndrome (MERS) (3). A higher mortality rate was recently suggested in patients with COVID-19 who had preexisting diabetes (4); according to the Chinese Centers for Disease Control and Prevention, COVID-19 case-fatality rates in patients with diabetes were around $7.3 \%$, versus $2.3 \%$ in the general Chinese population.

We aimed to investigate the magnitude of this risk and its dependency on age. We performed a systematic search and meta-analysis for clinical reports of COVID-19 infection which included detailed descriptions of patients' clinical profile - specifically, reporting information about the presence of diabetes at admission. The search strategy included the terms "clinical characteristics" AND "diabetes" AND "COVID-19" OR "SARS COV2" OR "coronavirus" OR "2019 n-Cov", and yielded 7 records, all of them case series from China. The clinical status at admission was divided into severe (requiring intensive care or having an oxygen saturation $<90 \%$ ) or mild-to-moderate (not requiring ICU or oxygen saturation $>90 \%$ ). The meta-analysis included a total of 1592 patients, 138 with a previous diagnosis of diabetes and 1454 without diabetes. Among those with diabetes, 59 (42.75\%) developed severe COVID-19 compared to $256(17.60 \%)$ of non-T2DM patients, resulting in an odds ratio of $3.53(95 \%$ confidence interval 1.48 to $8.39 ; I^{2} 64 \%$; for heterogeneity $=0.011$ ) (Figure 1 ). The high heterogeneity of this analysis suggests that other factors could nonetheless be involved in the higher risk of this population. To address this issue, we performed a random meta-analysis with meta-regression using the mean age of patients as a covariate; there was no impact on our initial results.

Diabetes mellitus appears to be a major, age-independent risk factor for severity of COVID-19. Further studies are necessary to address mechanisms by which diabetes may affect the prognosis of COVID-19 and how improving glycemic control might impact the course of the disease.

Acknowledgements: M.C.B. is the guarantor of the contents of the article, had full access to all the data in the study and takes responsibility for the integrity of the data and the accuracy of the data analysis.
Departamento de Emergência, Hospital de Clínicas de Porto Alegre, Universidade Federal do Rio Grande do Sul, Porto Alegre, RS, Brasil ${ }^{2}$ Serviço de Endocrinologia, Hospital de Clínicas de Porto Alegre, Universidade Federal do Rio Grande do Sul, Porto Alegre, RS, Brasil

Correspondence to: Marcello C. Bertoluci mbertoluci@hcpa.edu.br

Received on Apr/16/2020 Accepted on Apr/22/2020 DOI: $10.20945 / 2359-3997000000256$ 
Author

OR $(95 \% \mathrm{CI}) \quad$ Weight $(\%)$

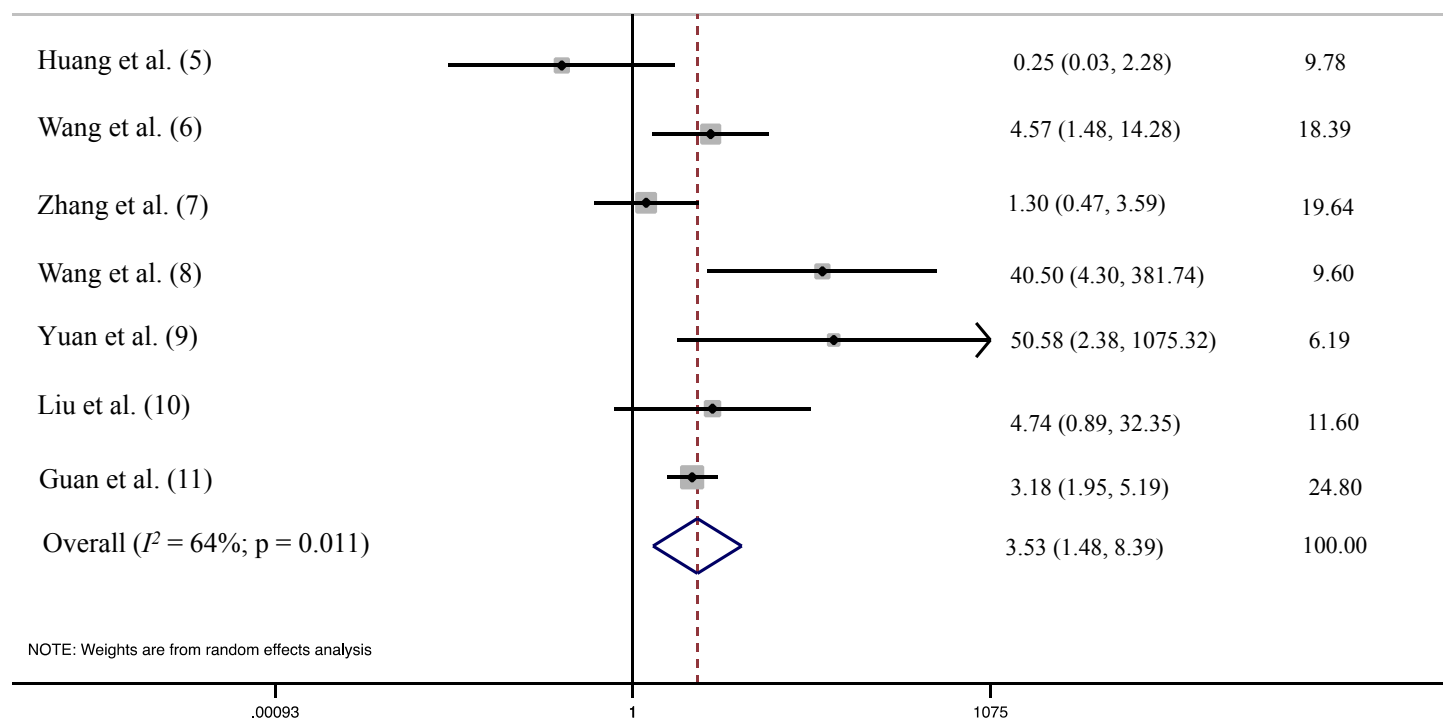

Figure 1. Forest-plot showing association of diabetes and severity of COVID-19, obtained from7descriptive studies.

\section{REFERENCES}

1. Schoen K, Horvat N, Guerreiro NFC, de Castro I, de Giassi KS. Spectrum of clinical and radiographic findings in patients with diagnosis of $\mathrm{H} 1 \mathrm{~N} 1$ and correlation with clinical severity. BMC Infect Dis. 2019;19(1):964.

2. Yang JK, Feng Y, Yuan MY, Yuan SY, Fu HJ, Wu BY, et al. Plasma glucose levels and diabetes are independent predictors for mortality and morbidity in patients with SARS. Diabet Med. 2006;23(6):623-8.

3. Song $Z, X u Y, B a o L$, Zhang $L, Y u P, Q u Y$, et al. From SARS to MERS, Thrusting Coronaviruses into the Spotlight. Viruses. 2019 Jan 14;11(1). pii: E59.

4. Harries A, Takarinda KC. F1000 Prime recommendation of Characteristics of and Important Lessons From the Coronavirus Disease 2019 (COVID-19) Outbreak in China: Summary of a Report of 72314 Cases From the Chinese Center for Disease Control and Prevention. F1000 - Post-Publication Peer Review of the Biomedical Literature 2020. Available from: https://doi.org/10.34 10/f.737420993.793572382.

5. Huang C, Wang Y, Li X, Ren L, Zhao J, HuY, et al. Clinical features of patients infected with 2019 novel coronavirus in Wuhan, China. Lancet. 2020 Feb 15;395(10223):497-506.
6. Wang Z, Yang B, Li Q, Wen L, Zhang R. Clinical Features of 69 Cases with Coronavirus Disease 2019 in Wuhan, China. Clin Infect Dis 2020. Available from: https://doi.org/10.1093/cid/ciaa272.

7. Zhang JJ, Dong $X, C a o$ YY, Yuan YD, Yang YB, Yan YQ, et al. Clinical characteristics of 140 patients infected with SARSCoV-2 in Wuhan, China. Allergy 2020. Available from: https://doi. org/10.1111/all.14238.

8. Wang A, Zhao W, Xu Z, Gu J.Timely blood glucose management for the outbreak of 2019 novel coronavirus disease (COVID-19) is urgently needed. Diabetes Res Clin Pract. 2020 Mar 13;162:108118.

9. Yuan $M$, Yin $W$, Tao Z, Tan W, Hu Y. Association of radiologic findings with mortality of patients infected with 2019 novel coronavirus in Wuhan, China. PLoS One 2020;15:e0230548.

10. Liu W, Tao ZW, Lei W, Ming-Li Y, Kui L, Ling Z, et al. Analysis of factors associated with disease outcomes in hospitalized patients with 2019 novel coronavirus disease. Chin Med J 2020. Available from: https://doi.org/10.1097/CM9.0000000000000775.

11. Guan WJ, Ni ZY, Hu Y, Liang WH, Ou CQ, He JX, et al. Clinical Characteristics of Coronavirus Disease 2019 in China. N Engl J Med 2020. Available from: https://doi.org/10.1056/NEJMoa2002032. 